\title{
Preparation and spectroscopic analysis of zinc oxide nanorod thin films of different thicknesses
}

\author{
Md. Nasrul Haque Mia ${ }^{1, *}$, Sardar Masud Rana ${ }^{1}$, Md. Firoz Pervez ${ }^{1}$, \\ Mohammad Reefaz Rahman ${ }^{2}$, Md. Khalid Hossain ${ }^{1}$, Abdul Al Mortuza ${ }^{1}$, \\ MOHAMmad Khairul BASHeR ${ }^{1}$, MAHBubul HoQ ${ }^{1}$ \\ ${ }^{1}$ Institute of Electronics, Atomic Energy Research Establishment, Bangladesh Atomic Energy Commission, Savar, Dhaka, \\ Bangladesh \\ ${ }^{2}$ University of Liberal Arts Bangladesh (ULAB)
}

\begin{abstract}
Zinc oxide thin films with different thicknesses were prepared on microscopic glass slides by sol-gel spin coating method, then hydrothermal process was applied to produce zinc oxide nanorod arrays. The nanorod thin films were characterized by various spectroscopic methods of analysis. From the images of field emission scanning electron microscope (FESEM), it was observed that for the film thickness up to $200 \mathrm{~nm}$ the formed nanorods with wurtzite hexagonal structure were uniformly distributed over the entire surface substrate. From X-ray diffraction analysis it was revealed that the thin films had good polycrystalline nature with highly preferred c-axis orientation along $\left(\begin{array}{lll}0 & 0 & 2\end{array}\right)$ plane. The optical characterization done by UV-Vis spectrometer showed that all the films had high transparency of $83 \%$ to $96 \%$ in the visible region and sharp cut off at ultraviolet region of electromagnetic spectrum. The band gap of the films decreased as their thickness increased. Energy dispersive X-ray spectroscopy (EDS) showed the presence of zinc and oxygen elements in the films and Fourier transform infrared spectroscopy (FT-IR) revealed the chemical composition of $\mathrm{ZnO}$ in the film.
\end{abstract}

Keywords: ZnO nanorod; ZnO thin film; sol-gel; hydrothermal growth; thickness effect

\section{Introduction}

Nanosized metal oxides show a drastic change in properties in comparison to their bulk counterparts because of their surface tailoring capability, large surface to volume ratio, reactive morphology, etc. [1,2]. After achieving a nanoscaled shape, a large number of atoms exist on the metal surface, which makes the reactivity of the surface significantly enhanced with changing properties. Recently, $\mathrm{ZnO}$ has attracted researchers' attention due to its excellent capability of formation nanostructured form easily, large electron mobility, abundance in nature and large isoelectric point $[3,4]$.

Crystalline $\mathrm{ZnO}$, belonging to II-VI semiconductor group, is a semiconductor, mostly of wurtzite hexagonal structure with a direct wide band gap of about $3.37 \mathrm{eV}$, exhibiting a large

*E-mail: nasrul_apece@yahoo.com exciton binding energy of $60 \mathrm{meV}$ at room temperature $[1,4,6]$. It is a low cost, nontoxic material that exhibits good thermal conductivity and excellent thermal and mechanical stability [15]. It shows large transparency in the visible region and large absorbance in the UV region of electromagnetic spectrum. Due to its such unique properties, it has versatile applications in various fields such as optoelectronics, photonics, photovoltaics, piezoelectric sensors, etc. [6, 7]. $\mathrm{ZnO}$ nanostructures are an excellent material for fabricating optical waveguides, light emitting diodes (LED), lasers, thin film transistors, solar cell window layers, actuators, chemical and gas sensors, etc. [6, 7]. $\mathrm{ZnO}$ nanostructures can be synthesized in many nanostructure forms, such as nanorods, nanowires, nanotubes, nanowalls, nanobelts [810], etc. using different methods such as hydrothermal method [8], chemical bath deposition, thermal evaporation, chemical vapor deposition, molecular beam epitaxy, microwave assisted 
chemical precipitation, spray pyrolysis [11-14], etc. All of these synthesis techniques have some distinguished advantages in comparison with others. Among them, hydrothermal growth method is convenient for growing uniformly aligned one dimensional nanorods or nanowires by varying growth parameters, such as solution $\mathrm{pH}$ value, reaction time and temperature, type of used chemical, molar concentration, etc. [8, 9]. The development of nanorods is also affected by the thickness of the film. Sharma et al. [14] used a sol-gel method to prepare thin films with different thicknesses and they found that as the film thickness increased, the film growth mode was shifted towards lateral direction from vertical direction. Zhong et al. [15] also reported the similar result. Mortezaali et al. [16] prepared $\mathrm{ZnO}$ nanostructured thin film by spray method and they revealed that the growth mode had changed from lateral to vertical when the film thickness was increased. However, the effect of film thickness on $\mathrm{ZnO}$ nanorod formation on a glass substrate by sol-gel method was less investigated.

In this study, our goal is to investigate the film thickness effect on $\mathrm{ZnO}$ nanorod formation. For this purpose, we developed $\mathrm{ZnO}$ thin films of three different thicknesses on glass substrates by sol-gel method and then the thin films were converted into nanorod structures by simple hydrothermal technique. The effects of thickness variation of the formed nanorod structure on optical, structural, morphological and mechanical properties of $\mathrm{ZnO}$ thin films were also investigated.

\section{Sample preparation}

\subsection{Zinc oxide $(\mathrm{ZnO})$ thin film seed layer preparation}

Zinc oxide $(\mathrm{ZnO})$ seed solution was prepared by using zinc acetate dehydrate $\left(\mathrm{Zn}\left(\mathrm{CH}_{3} \mathrm{COO}\right)_{2} \cdot 2 \mathrm{H}_{2} \mathrm{O}\right)$ as a precursor, 2-methoxy ethanol as a solvent and monoethanolamine as a solution stabilizer. The molar ratio of zinc acetate and monoethanolamine in the solution was kept at 1:1. At first, $1.31706 \mathrm{~g}$ zinc acetate was dissolved in $20 \mathrm{~mL}$ of 2-methoxy ethanol to prepare $0.3 \mathrm{M}$ zinc oxide solution. The solution was stirred rigorously by a magnetic stirrer placed over a hot plate. During this time, the temperature of the hot plate was kept at $75^{\circ} \mathrm{C}$. After $30 \mathrm{~min}$ of stirring, the solution became cloudy. Then, monoethanolamine was added in the solution drop by drop, which made the solution homogenously transparent. At this stage, the solution was continuously stirred for another 2 hours. Next, the solution was aged by keeping it at room temperature for 24 hours. After that, uniform transparent $\mathrm{ZnO}$ thin films were developed by sol-gel technique on a cleaned glass substrate. A conventional spin coater was used to deposit the $\mathrm{ZnO}$ solution on the cleaned glass substrate at $2500 \mathrm{rpm}$ for 30 seconds.

\subsection{Thermal analysis}

Fig. 1 shows the thermogravimetric analysis (TGA) curve of $\mathrm{ZnO}$ gel solution. From this curve, it is inferred that weight losses have occurred at two phases in the temperature range of $30{ }^{\circ} \mathrm{C}$ to $75{ }^{\circ} \mathrm{C}$ and $90{ }^{\circ} \mathrm{C}$ to $210{ }^{\circ} \mathrm{C}$. The evaporation of 2-methoxyethanol brought about the first weight loss, whereas the evaporation of water and the decomposition of monoethanolamine and residual organics caused the second weight loss. No weight loss has been observed above $210{ }^{\circ} \mathrm{C}$ and this allowed us to estimate the preheat temperature. The substrates were then preheated by placing them on a hot plate at $210{ }^{\circ} \mathrm{C}$ for 10 minutes.

In this fashion, the spin coating and preheat treatment processes were repeated several times to obtain $\mathrm{ZnO}$ films of three different thicknesses: $100 \mathrm{~nm}, 200 \mathrm{~nm}$ and $300 \mathrm{~nm}$. The thickness of the films was measured by Veeco Dektak-150 surface profiler. Finally, the samples were placed inside a conventional maple furnace for post heat treatment by annealing them at $500{ }^{\circ} \mathrm{C}$ for two hours.

\subsection{Growth of $\mathrm{ZnO}$ nanorods by hy- drothermal method}

A popular method, hydrothermal growth, was applied to convert the $\mathrm{ZnO}$ thin films into the nanorod structure. For this purpose, an aqueous solution of zinc nitrate hexahydrate and hexamethylenetetramine (HMTA) was prepared 


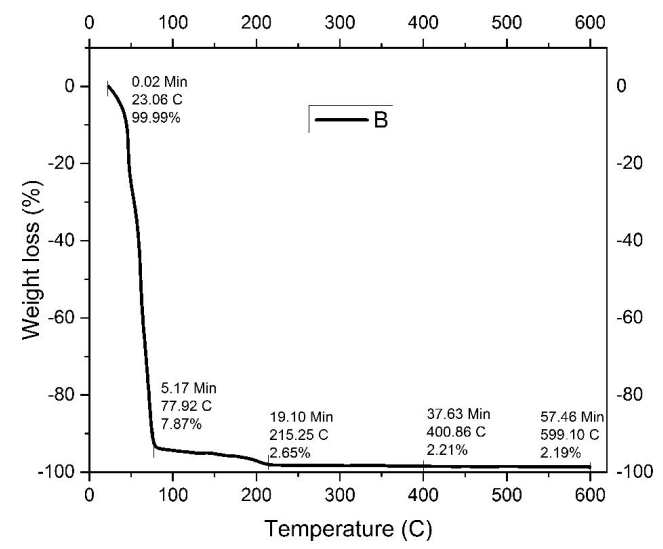

Fig. 1. Thermogravimetric analysis curve of $\mathrm{ZnO}$ gel solution.

by maintaining the concentration of the $\mathrm{Zn}\left(\mathrm{NO}_{3}\right)_{2}$ at $50 \mathrm{mM}$ and the molar ratio of the $\mathrm{Zn}\left(\mathrm{NO}_{3}\right)_{2}$ to HMTA at 1:1. To dissolve $\mathrm{Zn}\left(\mathrm{NO}_{3}\right)_{2}$ and HMTA powder in deionized water, the mixture was stirred using a magnetic stirrer for about 15 minutes at room temperature.

For growing the $\mathrm{ZnO}$ nanorods on the substrate film surface, the thin film samples were immersed in the aqueous solution by placing them at an upside down position. At this time, the samples that were immersed in the aqueous solution were heated at $85{ }^{\circ} \mathrm{C}$ for 6 hours in a laboratory oven. The heating temperature was fixed at $85^{\circ} \mathrm{C}$ because at this temperature the grown $\mathrm{ZnO}$ nanorods have the best morphology as well as optical and structural quality [17]. After completion of the nanorod growth process, the samples were rinsed thoroughly with deionized water, and then dried by a blower. Eventually, the $\mathrm{ZnO}$ nanorods on the glass substrate were heat-treated at $500{ }^{\circ} \mathrm{C}$ for two hours.

Three samples with seed layer thickness of $100 \mathrm{~nm}$ (sample 1), $200 \mathrm{~nm}$ (sample 2) and $300 \mathrm{~nm}$ (sample 3) thin films on which $\mathrm{ZnO}$ nanorods were grown were labeled as S1, S2, S3, respectively, and will be characterized in detail in the following section.

\section{Results and discussion}

\subsection{Elemental analysis}

Energy-dispersive X-ray spectroscopy (EDS) and Fourier transform infrared spectroscopy
(FT-IR) are two different analysis techniques used for elemental analysis of a compound material sample. These two analyses characterize constituent materials and chemical bonds as well as the sample purity. EDS analysis indicates the presence of all individual elements of any compound material sample, whereas from FT-IR analysis, vibrational properties of the compound material molecular bonds can be investigated.

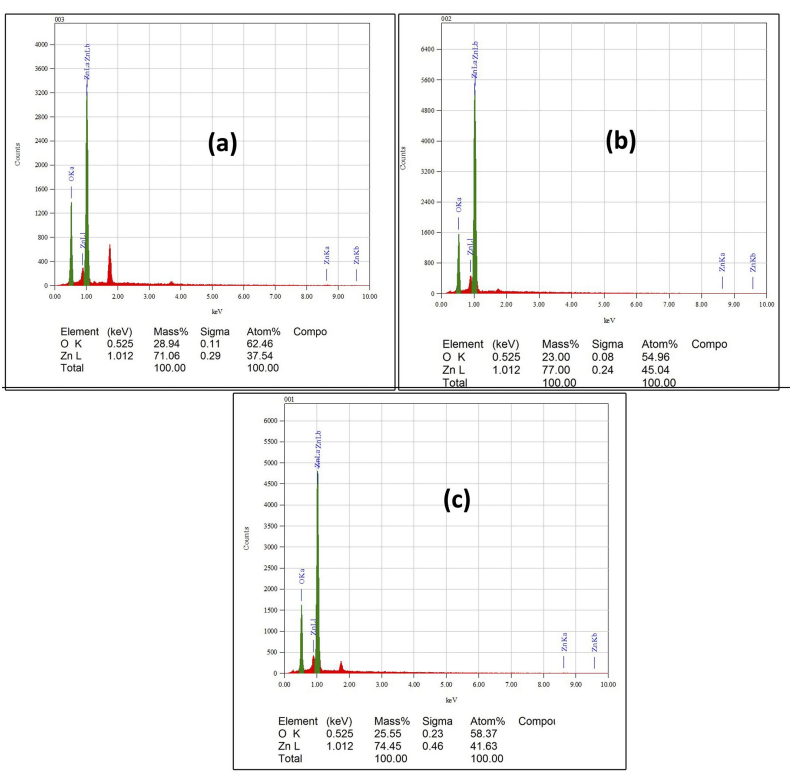

Fig. 2. EDS spectra of $\mathrm{ZnO}$ nanorod thin films: (a) sample-1(S1), (b) sample-2(S2), (c) sample$3(\mathrm{~S} 3)$.

\subsubsection{EDS analysis}

Fig. 2 shows the EDS spectra of the $\mathrm{ZnO}$ thin films of three different thicknesses. The two peaks at $1.012 \mathrm{keV}$ and $0.525 \mathrm{keV}$ for the three samples in green color validate the presence of zinc and oxygen respectively. Another peak at approximately $1.8 \mathrm{keV}$ in red color indicates the presence of silicon in the three samples since the films were developed on glass substrates. In addition, the inset tables of Fig. 2 show the amount of atomic percentages as well as mass percentages of zinc and oxygen present in the three samples. Among them, $200 \mathrm{~nm}$ film thickness sample contains the highest amount of zinc. 


\subsubsection{FT-IR analysis}

The FT-IR spectra of the $\mathrm{ZnO}$ nanorod thin film samples that were taken over the range of $400 \mathrm{~cm}^{-1}$ to $4000 \mathrm{~cm}^{-1}$ (Fig. 3) indicate the chemical composition of the thin films.

The characteristic absorption peaks around $426 \mathrm{~cm}^{-1}$ to $432 \mathrm{~cm}^{-1}, 483 \mathrm{~cm}^{-1}$ to $484 \mathrm{~cm}^{-1}$ and $588 \mathrm{~cm}^{-1}$ to $592 \mathrm{~cm}^{-1}$ for all the samples suggest $\mathrm{Zn}-\mathrm{O}$ stretching modes related to $\mathrm{ZnO}$ nanorods. In addition, broad absorption peaks band from $3000 \mathrm{~cm}^{-1}$ to $3650 \mathrm{~cm}^{-1}$ attributed to the O-H (hydroxyl) stretching vibrations, caused by both molecular and dissociative absorption of water, appeared from the growth process as well as adsorption from the atmosphere while annealing $[32,35,36]$.

Absorption peaks at $1479 \mathrm{~cm}^{-1}$ to $1480 \mathrm{~cm}^{-1}$ are due to the asymmetric and symmetric stretching vibrations of $\mathrm{C}=\mathrm{O}$ group. Moreover, absorption peaks at $2847 \mathrm{~cm}^{-1}$ and $2916 \mathrm{~cm}^{-1}$ to $2917 \mathrm{~cm}^{-1}$ band imply the existence of asymmetrical and symmetrical $\mathrm{C}-\mathrm{H}$ bonds $[32,37]$.

$\mathrm{C}=\mathrm{O}$ and $\mathrm{C}-\mathrm{H}$ bonds result from carboxylate (COO-) group which is a constituent of acetate that was present in the precursor solution [32]. Furthermore, at high temperature, in presence of water and $\mathrm{ZnO}$ without any catalyst, $\mathrm{CO}_{2}$ can be easily and selectively reduced into formic acid $(\mathrm{HCOOH})$. However, the predominant pathway at high temperature water is decomposition of formic acid that produces $\mathrm{CO}_{2}, \mathrm{CO}$ and $\mathrm{H}_{2}$ [38]. Annealing of $\mathrm{ZnO}$ in air might produce small amount of formic acid that could be another reason of $\mathrm{C}=\mathrm{O}$ and $\mathrm{C}-\mathrm{H}$ group formation.

\subsection{SEM characterization}

Fig. 4 shows the top view of SEM images of the synthesized $\mathrm{ZnO}$ nanorod samples on glass substrates of three different thicknesses. From the SEM images, it is found that two sample films have been entirely converted into uniformly distributed nanorod structures with random orientation while one film was converted into nanostructured form. Hence, it is observed that the thickness of the film

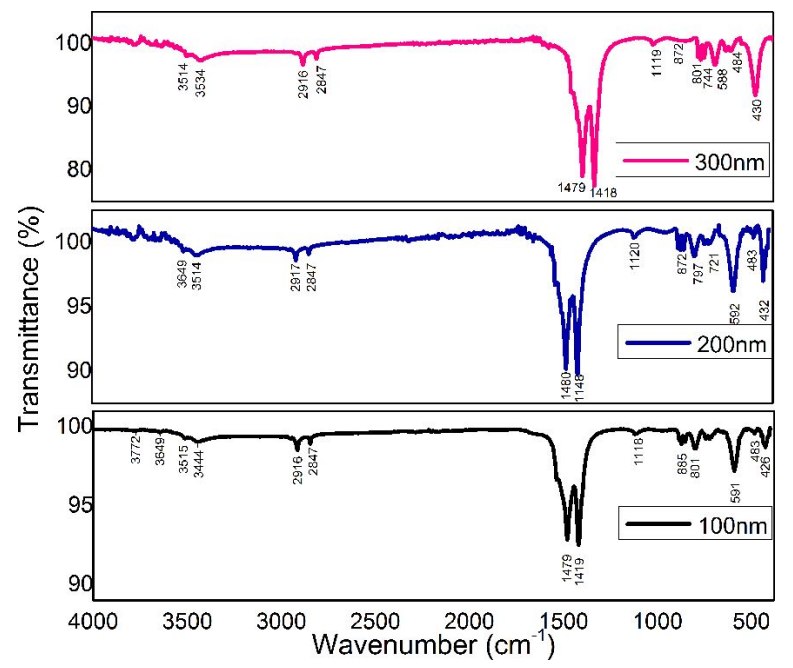

Fig. 3. FT-IR spectra of $\mathrm{ZnO}$ nanorod thin films: sample S1 $(100 \mathrm{~nm}), \mathrm{S} 2(200 \mathrm{~nm}), \mathrm{S} 3(300 \mathrm{~nm})$.

has a great influence on the nanostructure form of the thin film.

Fig. 4a and Fig. 4b show the magnified view of sample 1 which reveals that vertically aligned well organized and uniformly distributed nanorods were formed here. The developed nanorods have a hexagonal shape along c-axis and the average diameters of the nanorods are in the range of $30 \mathrm{~nm}$ to $50 \mathrm{~nm}$.

In case of sample 2 which has the thickness higher than sample 1, it is shown that randomly distributed vertically as well as horizontally aligned nanorods were formed. Hence, as the thickness increased, a transition in the growth mode shifted from vertical to lateral direction. Sharma et al. [14] and Zhong et al. [15] found the similar result.

In case of sample 3, which has the thickness higher than the rest two, $\mathrm{ZnO}$ nanostructures were formed as grains on the substrate surface instead of nanorods.

The size and shape of the developed nanorods strongly depend on the growth time. Roza et al. [25] investigated the formation of $\mathrm{ZnO}$ nanorods by varying the growth time. They found that complete nanorod structures had not developed on the substrate surface for a short interval of growth time of 2 hours. At this time, the $\mathrm{ZnO}$ 
nanostructures were formed in the form of single nanorods like grains. Perfect hexagonal shaped $\mathrm{ZnO}$ nanorods were formed when the growth time was at least 4 hours and at that time the orientation of the nanorods was along the c-axis. The phenomena can be explained by the thickness of the films. At a constant growth time, vertically aligned perfect hexagonally shaped nanorods were developed in the lower thickness film of $100 \mathrm{~nm}$. As the thickness increased to $200 \mathrm{~nm}$, the nanorod formation tended to shift from vertical direction towards lateral direction. A further increase in the thickness of the film to $300 \mathrm{~nm}$ resulted in the formation of single nanorods on the film surface instead of perfect nanorod structure.
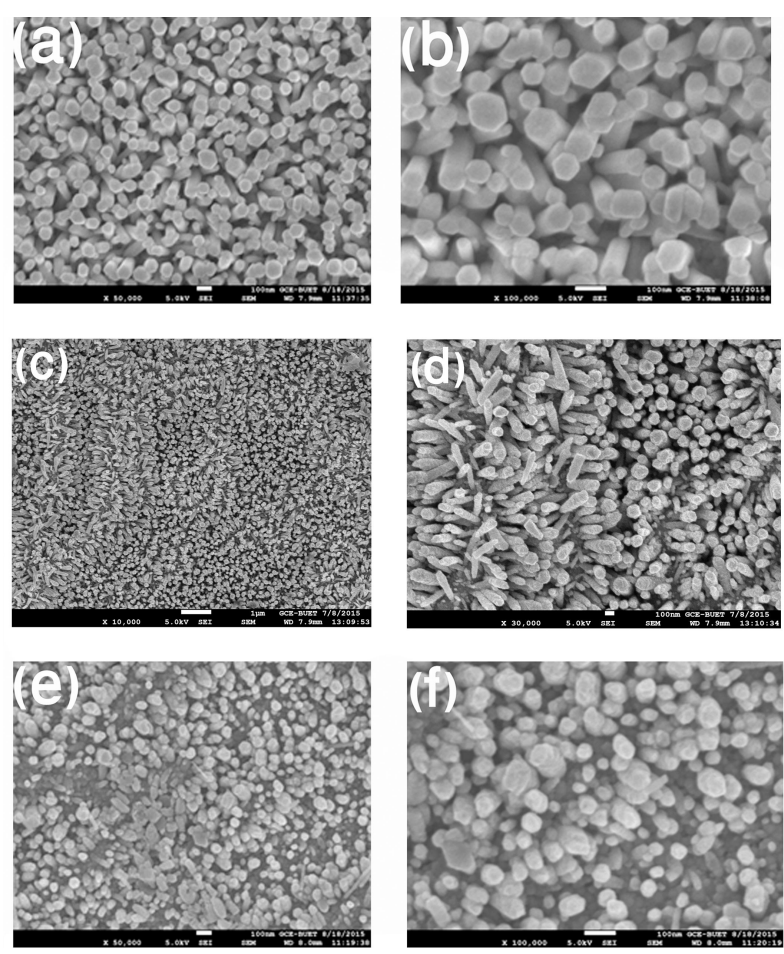

Fig. 4. High resolution SEM images of $\mathrm{ZnO}$ nanorods: (a) and (b) for S1, (c) and (d) for S2, (e) and (f) for S3 Sample.

\subsection{XRD characterization}

The crystalline structure of three different thicknesses $\mathrm{ZnO}$ nanorod thin films developed on glass substrates was studied using X-ray diffraction technique in $2 \theta$ range of $0^{\circ}$ to $80^{\circ}$. Four distinguished diffracted peaks in XRD patterns (Fig. 5) can be observed at $2 \theta$ positions: $31.40^{\circ}, 34.82^{\circ}, 36.58^{\circ}$, $73.22^{\circ}$ for sample $1 ; 31.46^{\circ}, 34.86^{\circ}, 36.64^{\circ}, 73.22^{\circ}$ for sample 2 ; and $31.32^{\circ}, 34.70^{\circ}, 36.54^{\circ}, 73.16^{\circ}$ for sample 3 . These peaks correspond to $\left(\begin{array}{lll}1 & 0 & 0\end{array}\right)$,

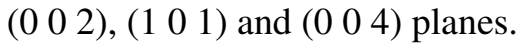

The strong narrow diffraction peaks related to (lll $\left.\begin{array}{lll}0 & 0 & 2\end{array}\right)$ plane imply good crystalline films with wurtzite structure of hexagonal shape along c-axis. Among the three samples, sample 2 exhibits the strongest $\left(\begin{array}{lll}0 & 0 & 2\end{array}\right)$ diffraction peak indicating that sample 2 has better quality crystalline structure. A similar result was reported by Sharma et al. [14] who found that the intensity of the $\left(\begin{array}{lll}0 & 0 & 2\end{array}\right)$ plane diffraction peak increased up to $200 \mathrm{~nm}$ film thickness. This results from the fact that in a certain thickness range of $\mathrm{ZnO}$ film, the crystalline quality is gradually enhanced with the increase in film thickness [18].

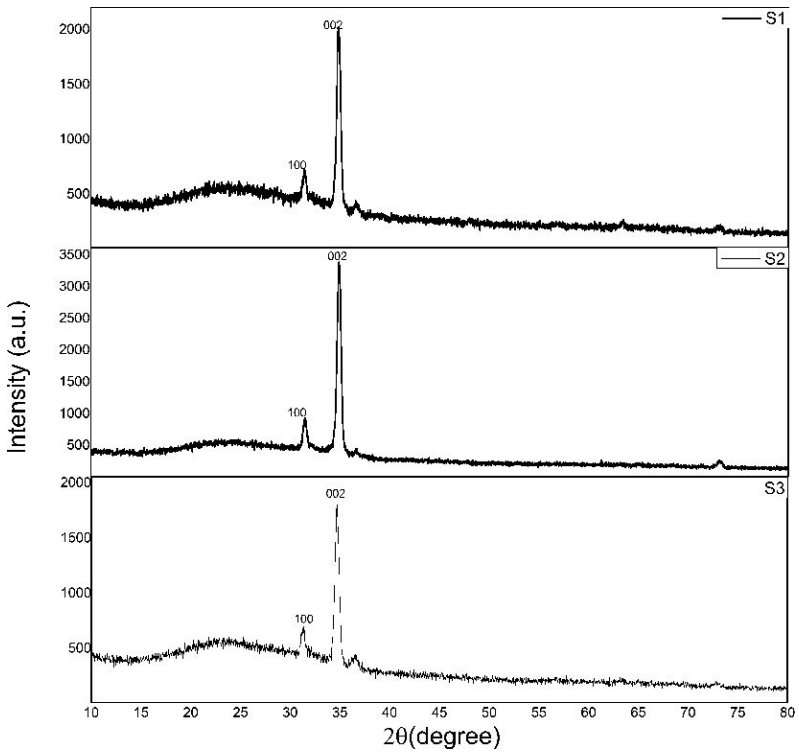

Fig. 5. XRD spectra of $\mathrm{ZnO}$ nanorod thin films of different thicknesses.

Grain size: an average grain size D of the crystalline structure can be obtained from Scherrer equation [19] as:

$$
D=\frac{k \lambda}{\beta \cos \theta}
$$

where $\lambda$ stands for the wavelength of the incident $\mathrm{X}$-ray $\mathrm{CuK} \alpha$ radiation, $\mathrm{k}$ is a constant (0.9), $\beta$ is 
the full width at half maximum and $\theta$ is the Bragg angle of respective plane (llll $\left.0 \begin{array}{ll}0 & 2\end{array}\right)$ peak.

Interplanar distance: the distance between the planes can be found by the following formula [20] as:

$$
d=\frac{\lambda}{2 \sin \theta}
$$

where $\mathrm{d}$ is the interplanar distance.

Moreover, the lattice constants a and c have been calculated by the following formula [21] as:

$$
\begin{aligned}
& a=\frac{\lambda}{\sqrt{3} \sin \theta} \\
& c=\lambda / \sin \theta
\end{aligned}
$$

The strain along c-axis [18] and the strain along a-axis [19] can be calculated from the formulas as:

$$
\varepsilon_{c}=\frac{\left(c-c_{0}\right)}{c_{0}} \times 100 \%
$$

and:

$$
\varepsilon_{a}=\frac{\left(a-a_{0}\right)}{a_{0}} \times 100 \%
$$

where $\epsilon_{\mathrm{c}}$ and $\epsilon_{\mathrm{a}}$ are the strains along c-axis and a-axis, respectively.

The dislocation density can be calculated by the following formula [22] as:

$$
\delta=\frac{1}{D^{2}} \text { lines } / \mathrm{m}^{2}
$$

The stress of the films is calculated by the biaxial strain model using equation 8 which is valid for the hexagonal lattice [33]:

$$
\text { Stress } \sigma=\frac{2 C_{13}^{2}-C_{33}\left(C_{11}-C_{12}\right)}{2 C_{13}} \cdot \frac{c-c_{0}}{c_{0}}
$$

$$
b_{1}=\sqrt{\frac{a^{2}}{3}+\left(\frac{1}{2}-u\right)^{2} c^{2}}
$$

In addition to the nearest neighbors, there are three types of second-nearest neighbors designated as $b_{1}^{\prime}$ (one along the c-direction), $b_{2}^{\prime}$ (six of them) and $b_{3}^{\prime}$ (three of them) with the bond lengths:

$$
b_{1}^{\prime}=c(1-u)
$$

$$
b_{2}^{\prime}=\sqrt{a^{2}+(u c)^{2}}
$$

$$
b_{3}^{\prime}=\sqrt{\frac{4 a^{2}}{3}+\left(\frac{1}{2}-u\right)^{2} c^{2}}
$$

Bond angles $\alpha$ and $\beta$ are given by:

$$
\alpha=\frac{\pi}{2}+\cos ^{-1}\left[\left(\sqrt{1+3\left(\frac{c}{a}\right)^{2}\left(\frac{1}{2}-u\right)^{2}}\right)^{-1}\right]
$$

The values used for $\mathrm{c}_{\mathrm{ij}}$ (elastic constants of single crystal $\mathrm{ZnO}$ ) are $\mathrm{C}_{11}=208.8 \mathrm{GPa}$, $\mathrm{C}_{33}=213.8 \mathrm{GPa}, \mathrm{C}_{12}=119.7 \mathrm{GPa}, \mathrm{C}_{13}=$ 104.2 GPa [34]. $\beta=2 \sin ^{-1}\left[\left(\sqrt{\frac{4}{3}+4\left(\frac{c}{a}\right)^{2}\left(\frac{1}{2}-u\right)^{2}}\right)^{-1}\right]$ 
Table 1 and Table 2 present various lattice parameter values calculated by the above equations. Fig. 6 and Fig. 7 illustrate the effect of seed layer thickness on various structural parameters. It is observed that among the samples, sample 2 has smallest grain size, lattice constant, interplanar distance, bond angle and stress which leads to more uniform crystal structure. This observation is supported by the SEM images which show that sample 2 has more oriented and uniformly distributed nanorods than other samples.
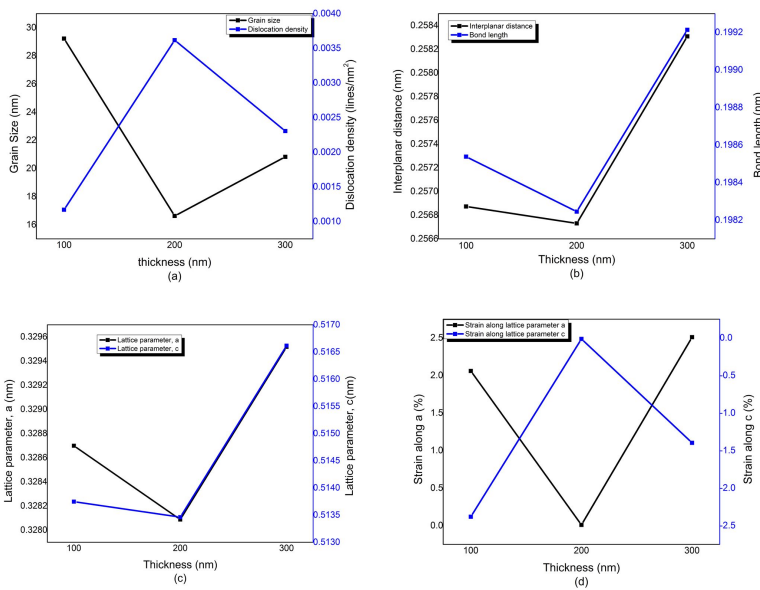

Fig. 6. Variation of (a) grain size and dislocation density (b) interplanar distance and bond length (c) lattice parameter a and lattice parameter c, (d) strain along a-axis and strain along c-axis, with film thickness.

\subsection{Optical properties}

\subsubsection{Transmittance, absorption coefficient} and absorption depth

Optical transmittance and absorbance measurements were carried out from $300 \mathrm{~nm}$ to $800 \mathrm{~nm}$ wavelength range (Fig. 8). All samples exhibit a high transmittance level (about $83 \%$ to $96 \%$ ) within the visible range where sample 1 and sample 2 show more uniform transmittance characteristics than that of sample 3, indicating that the uniformity of transmittance level decreased with an increase in the film thickness. Moreover, all the three samples experience a sharp cut-off at ultraviolet (UV) range at around $380 \mathrm{~nm}$ demonstrating high

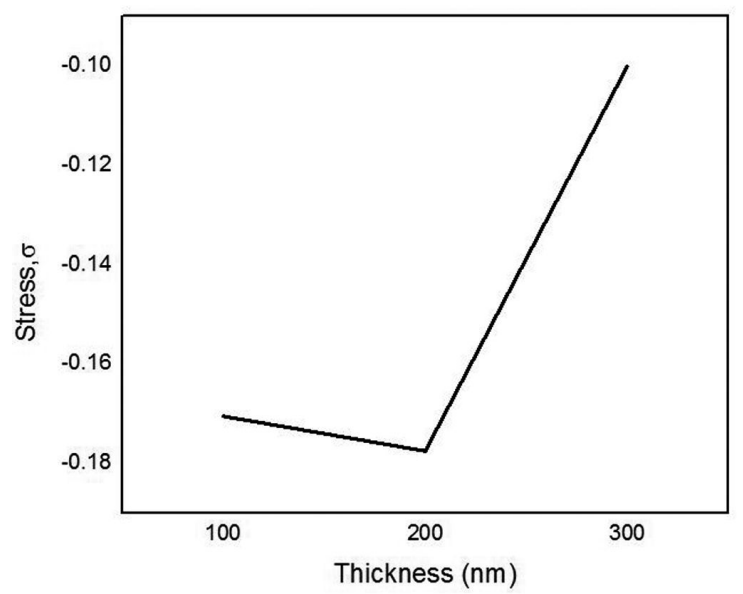

Fig. 7. Variation of stress $(\sigma)$ with respect to various thicknesses of $\mathrm{ZnO}$ nanorod thin films.

UV light absorption that leads to the possible use of $\mathrm{ZnO}$ nanorods in $\mathrm{UV}$ detection [26].

Absorption coefficient, which is related to the characteristics of a material and wavelength of incident light determines the light absorbing properties of the material. Another term: absorption depth, defined as the depth at which the amplitude of the intensity of the light is decreases by $1 / \mathrm{e}$ $(37.3 \%)$ [28], can be determined from the reciprocal of the absorption coefficient.

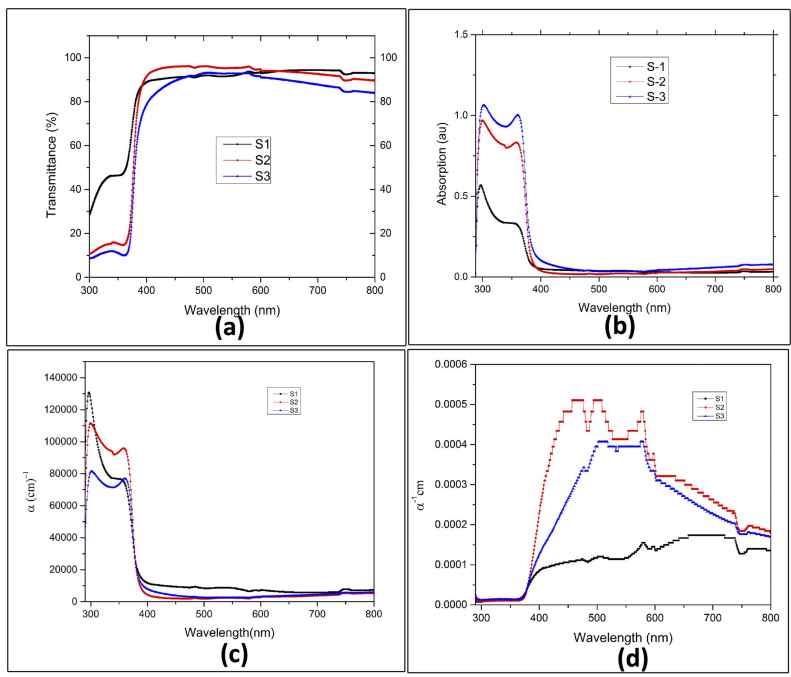

Fig. 8. (a) Transmittance spectra (b) absorption spectra (c) absorption coefficient and (d) absorption depth, as a function of wavelength of $\mathrm{ZnO}$ nanorod samples. 
Table 1. Structural bond length parameters according to their distance inside the $\mathrm{ZnO}$ nanorod structure.

\begin{tabular}{lccccc}
\hline Thickness [nm] & $\begin{array}{c}\text { Nearest-neighbor } \\
\text { bond length along } \\
\text { c-direction, b [nm] }\end{array}$ & $\begin{array}{c}\text { Nearest- } \\
\text { neighbor bond } \\
\text { length off } \\
\text { c-axis, } \mathrm{b}_{1}[\mathrm{~nm}]\end{array}$ & $\begin{array}{c}\text { Second } \\
\text { nearest-neighbor, } \\
\mathrm{b}_{1}^{\prime}[\mathrm{nm}]\end{array}$ & $\begin{array}{c}\text { Second } \\
\text { nearest-neighbor } \\
\text { bond length, } \mathrm{b}_{2}^{\prime} \\
{[\mathrm{nm}]}\end{array}$ & $\begin{array}{c}\text { Second } \\
\text { nearest-neighbor } \\
\text { bond length, } \mathrm{b}_{3}^{\prime} \\
{[\mathrm{nm}]}\end{array}$ \\
\hline \hline 100 & 0.198537903 & 0.256873 & 0.315209 & 0.384005 & 0.382952 \\
200 & 0.198244996 & 0.256731 & 0.315217 & 0.383331 & 0.382263 \\
300 & 0.199213492 & 0.258308 & 0.317403 & 0.385055 & 0.383986 \\
\hline
\end{tabular}

Table 2. Structural parameters showing positional parameter and bond angles $\alpha, \beta$.

\begin{tabular}{lccc}
\hline $\begin{array}{c}\text { Thickness } \\
{[\mathrm{nm}]}\end{array}$ & $\begin{array}{c}\text { Positional } \\
\text { parameter, } \mathrm{u}\end{array}$ & $\begin{array}{c}\text { Bond angle, } \\
\alpha\left[{ }^{\circ}\right]\end{array}$ & $\begin{array}{c}\text { Bond angle, } \\
\beta\left[{ }^{\circ}\right]\end{array}$ \\
\hline \hline 100 & 0.386450892 & 107.0863234 & 102.6732397 \\
200 & 0.386095002 & 107.1578239 & 102.5479023 \\
300 & 0.385612311 & 107.2550546 & 102.3770435 \\
\hline
\end{tabular}

The absorption coefficient $\alpha$ can be determined by the relation [27] as:

$$
\alpha=\frac{2.303 A}{t}
$$

where $\mathrm{A}$ and $\mathrm{t}$ stand for absorbance and thickness of a film, respectively.

\subsubsection{Optical bandgap and Urbach energy}

Optical bandgap: according to Tauc relationship [29]:

$$
(\alpha h v)^{\frac{1}{n}}=A\left(h v-E_{g}\right)
$$

where $\alpha, E_{g}, v, h$ denote absorption coefficient, energy band gap, frequency of radiation and Planck constant, respectively, and $\mathrm{A}$ is a constant.

The value of $\mathrm{n}$ is different for different types of transition materials. For direct transition material $\mathrm{n}=2$ and for indirect transition material $\mathrm{n}=1 / 2$. Since $\mathrm{ZnO}$ is a direct transition material, hence $(\alpha \mathrm{h} v)^{1 / 2}=\mathrm{A}\left(\mathrm{h} v-\mathrm{E}_{\mathrm{g}}\right)$. To determine the optical band gap, the absorption coefficient data $(\alpha h v)^{2}$ were plotted against photon energy hv as shown in Fig. 8a. Then, by extrapolating the linear portion to the $x$-axis of the $(\alpha h v)^{2}$ vs. hv plot, the optical band gap was determined.

Urbach energy: In optical absorption process, near band edges, the electrons at the uppermost position of the valance band get excited to enter the lowermost position of the conduction band. During this time, if the electrons have experienced any disorder caused by amorphous solids or defective crystalline structures or thermal vibration in crystals, the density states of electrons along both conduction band and valance band edges exhibit tails towards the energy band gap which is termed as Urbach tail; and the energy associated with the Urbach tail is referred to as Urbach energy [30]. Urbach energy (Fig. 8b) can be determined by the formula as [31]:

$$
\alpha=\alpha_{\circ} \exp \left(\frac{h v}{E_{u}}\right)
$$

where $E_{u}$ is Urbach energy, $\alpha$ is absorption coefficient, $\alpha_{\circ}$ is a constant and hv is photon energy.
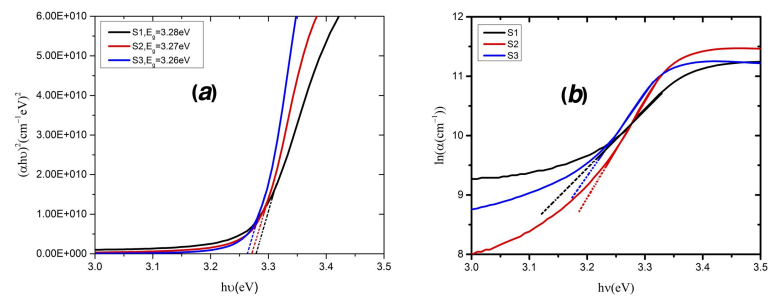

Fig. 9. (a) Optical bandgap of $\mathrm{ZnO}$ nanorod samples (b) Urbach plots of different thicknesses $\mathrm{ZnO}$ nanorod thin films.

Fig. 9a shows the optical bandgap of $\mathrm{ZnO}$ nanorods. The calculated band gaps are $3.28 \mathrm{eV}$, $3.27 \mathrm{eV}$ and $3.26 \mathrm{eV}$ for the $100 \mathrm{~nm}, 200 \mathrm{~nm}$ and $300 \mathrm{~nm} \mathrm{ZnO}$ nanorod thin films, respectively. Optical bandgap of the samples was less than that of bulk $\mathrm{ZnO}$. It decreased monotonically with thickness and number of deposited $\mathrm{ZnO}$ layers. This is similar to the result reported by Tüzemen et al. [39] 
and Lee et al. [40]. A direct relation between lattice constant and optical bandgap is observed, as well (Fig. 10a). The decrease in the band gap might occur owing to defects associated with the presence of cavities and surface roughness.
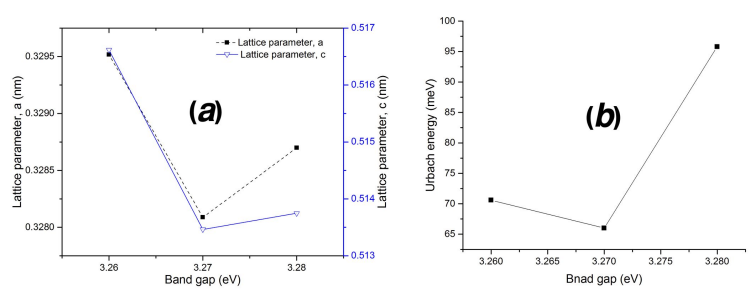

Fig. 10. Correlation between (a) optical bandgap and lattice constant (b) optical bandgap and Urbach energy.

Fig. 9b shows $\ln \alpha$ vs. photon energy $\mathrm{h} v$ curve for the three samples. By extrapolating the linear portion of the curve, the reciprocal value of the slope of the linear part gives the Urbach energy. The estimated Urbach energies are $95.8 \mathrm{meV}$, $66 \mathrm{meV}$ and $70.6 \mathrm{meV}$ for samples 1, 2 and 3, respectively. Urbach energy is a function of structural disorder - higher Urbach energy and longer Urbach tail indicate more disorders caused by defective crystalline structure or amorphous solid. Moreover, Urbach energy does not change monotonically with energy band gap (Fig. 10b). A similar trend was observed by Belahssena et al. [41]. Among the samples, the $200 \mathrm{~nm}$ sample has the least Urbach energy indicating less crystal disorder, which supports XRD analysis, as well.

\section{Conclusions}

Hydrothermal method was successfully applied to synthesize different thicknesses zinc oxide nanorod thin films at a constant growth temperature of $85{ }^{\circ} \mathrm{C}$. The growth of nanorod arrays strongly depends on the thickness of the films. The band gap decreased as the thickness of the films increased and the average diameter of the grain varied from $17 \mathrm{~nm}$ to $28 \mathrm{~nm}$. Based on different spectroscopic analysis results, it was revealed that the $200 \mathrm{~nm}$ thickness film showed the best crystalline quality, highest uniform transmittance level at the visible region and sharp cut off at the ultraviolet region of electromagnetic spectrum. Moreover, this $200 \mathrm{~nm}$ sample had the smallest grain size, lowest values of interplanar distance and lattice parameters, higher percentages of zinc and less Urbach energy. Hence, it was observed that at a constant growth temperature the grown nanorod arrays in $200 \mathrm{~nm}$ thickness film showed the best crystalline quality as well as optical and morphological characteristics. The spectroscopic analyses of the three samples indicated the effect of thickness variation on hydrothermally grown zinc oxide nanorods. However, more samples need to be investigated to explore changing behavior of various parameters in details to get the insight into correlation among these parameters.

\section{Acknowledgements}

The authors wish to acknowledge the kind support from the Department of Glass and Ceramic Engineering (GCE), BUET for SEM images and EDS; the Institute of Fuel Research \& Development (IFRD), BCSIR for XRD; ITBBR, AERE, BAEC for Muffle Furnace; and READ, IFRB, AERE, BAEC for UV-Vis Spectrometer.

\section{References}

[1] Wahab H.A., Salama A.A., El-Saeid A.A., Nur O., Willander M., Battisha I.K., Results Phys., 3 (2013), 46.

[2] Khun K., Ibupoto Z.H., Chey C.O., LU J., Nur O., Willander M., Appl. Surf. Sci., 268 (2013), 37.

[3] Zhou H., Li J., Bao S., Li J., LiU X., Jin P., Appl. Surf. Sci., 363 (2015), 532.

[4] Janotti A., Walle C.G.V., Rep. Prog. Phys., 72 (2009), 126501.

[5] Ali M.M., J. Basrah Res., 37 (2011), 49.

[6] KoŁodziejczak-Radzimska A., Jesionowski T., Materials, 7 (2014), 2833.

[7] ÖzGür Ü., Alivov Y.I., LIU C., TEKE A., Reshchikov M.A., DoĞAn S., Avrutin V., Cho S.J., MORKOÇD H., J. Appl. Phys., 98 (2005), 041301.

[8] Baruah S., Dutta J., Sci. Technol. Adv. Mat., 10 (2009), 13001

[9] Das R., Kumar A., Kumar Y., Sen S., Shirage P.M., RSC Adv., 5 (2015), 60365.

[10] SKOMPSKA M., ZAREBSKA K., Electrochim. Acta, 127 (2014), 467.

[11] Mortezanli A., Taheri O., Hosseini Z.S., Microelectron. Eng., 151 (2016), 19.

[12] Sangari N.U., Devi S.C., J. Solid State Chem., 197 (2013), 483 
[13] Mariappan R., PONNUSWAMY V., Chandra Bose A., Chithambararaj A., Suresh R., RAGAVENDAR M., Superlattice. Microst., 65 (2014), 184.

[14] Sharma M., Mehra R.M., Appl. Surf. Sci., 255 (2008), 2527

[15] Zhong B.Z., FAng G.J., WANG J.F., GUAN W.J., ZhAO X.Z., J. Appl. Phys., 101 (2007), 033713.

[16] Mortezanli A., TAheri O., Hosseini Z.S., Microelectron. Eng., 151 (2016), 19.

[17] Zhang S., Yan C., Zhang H., Lu G., Mater. Lett., 148 (2015), 1.

[18] Xu L., Li X., Chen Y., Xu F., Appl. Surf. Sci., 257 (2011), 4031.

[19] Farhat O.F., Halim M.M., Abdullah M.J., Ali M.K.M., Allam N.K., Beilstein J. Nanotech., 6 (2015), 720.

[20] Kashif M., Hashim U., Ali M.E., Ali S.M.U., RUSOP M., IbUPOTO Z.H., WILlANDER M., J. Nanomater., 2012 (2012), 452407.

[21] Foo K.L., Hashim U., Muhammad K., Voon C.H., Nanoscale Res. Lett., 9 (2014), 429.

[22] Mariappan R., Ponnuswamy V., Bose A.C., Chithambararaj A., Suresh R., RagaVenDAR M., Superlattice Microst., 65 (2014), 184.

[23] Srinivasan G., Kumar R.T.R., Kumar J., J. SolGel Sci. Techn., 43 (2007), 171.

[24] MoR KOC H., Handbook of Nitride Semiconductors and Devices: Materials Properties, Physics and Growth, Vol. 1, John Wiley \& Sons, New Jersey, 2009.

[25] Roza L., Rahman M.Y.A., Umar A.A., Salleh M.M., J. Alloy. Compd., 618 (2015), 153.

[26] Ji L.W., Peng S.M., Su Y.K., Young S.J., Wu C.Z., Cheng W.B., Appl. Phys. Lett., 94 (2009), 203106.

[27] Caglar M., Caglar Y., IliCan S., J. Optoelectron. Adv. M., 8 (2006), 1410.
[28] Borowicz P.B., J. Spectrosc., 2016 (2016), 1617063.

[29] Gupta R.K., Serbeti Z., Yakuphanoglu F., J. Alloy. Compd., 515 (2012), 96.

[30] RaI R.C., J. Appl. Phys., 113 (2013), 153508.

[31] Gadallah A.S., El-Nahass M.M., Condens. Matter Phys., 2013 (2013), 234546.

[32] Khan M.F., Ansari A.H., Hameedullah M., AHMAd E., Husain F.M., Zia Q., Baig U., ZaheER M.R., Alam M.M., Khan A.M., Alothman Z.A., Ahmad I., Ashraf G.M., Aliev G., Sci. Rep.-UK, 6 (2016), 27689.

[33] Xua L., Li X., Chen Y., Xu F., Appl. Surf. Sci., 257 (2011), 4031.

[34] Zhang D., Fan P., Cai X., Huang J., Ru L., Zheng Z., Liang G., Huang Y., Appl. Phys. A, 97 (2009), 437.

[35] Noei H., QIU H., WANG Y., LÖFFler E., Wöllb C., Muhler M., Phys. Chem. Chem. Phys., 10 (2008), 7092.

[36] Cheng X.L., Zhao H., Huo H., Gao S., Zhao J.G., Sensor. Actuat. B-Chem., 102 (2004), 248.

[37] Vijayalakshmi K., Karthick K., GopalakrISHNA D., Ceram. Int., 39 (2013), 4749.

[38] Jin F., ZENG X., LiU J., Jin Y., WANG L., ZhONG H., Yao G., Huo Z., Sci. Rep.-UK, 4 (2014), 4503.

[39] Tüzemen E.Ş., Eker S., KaVaK H., Esen R., Appl. Surf. Sci., 255 (2009), 6195.

[40] Lee J., Sorescu D.C., Deng X., J. Phys. Chem. Lett., 7 (2016), 1335.

[41] Belahssena O., Temam H.B., Lakel S., Benhaoua B., Benramache S., Gareh S., Optik, 126 (2015), 1487. 